\title{
Longwall top coal caving automation concept
}

\author{
Sergey Nikitenko $^{1 *}$, Ulf Kiessling ${ }^{2}$, Sergey Kizilov ${ }^{1}$, and Mikhail Nikitenko ${ }^{1}$ \\ ${ }^{1}$ Federal Research Center for Coal and Coal Chemistry, Siberian Branch, Russian Academy of \\ Sciences, Coal Mining Machine Engineering Laboratory, Kemerovo, 650000, Russia \\ ${ }^{2}$ Marco Systemanalyse und Entwicklung GmbH, Dachau, 85221, Germany
}

\begin{abstract}
This paper describes history of the longwall top coal caving technology. The devices capable to promote wider application of LTCC are discussed. The advantages, shortcomings and their elimination methods are specified. The authors designate the objectives to be met to implement the maximum potential of LTCC. The industry approach to these objectives is exemplified. The applicability of LTCC in combination with new-generation powered roof support with coal outlet in supported area in longwalls is discussed. The ways of finding solutions to the set problems are proposed.
\end{abstract}

\section{Introduction}

Top coal caving technologies is not a novelty. The first experimental tests of top coal caving were undertaken well before engineering of longwall mining systems and hydraulically-powered shield-type roof supports. In the USSR experiments with top coal caving in the supported area of roadways were initiated in the 1930s [1]. The whole process was accomplished manually, without assistance of machines: preparation of a work areaestablishment of a certain support-opening of an outlet-discharging of broken coal-closure of the outlet-loading of coal manually on a conveyor. Since the late 1940s, the top coal caving technology came into operation in France, with coal outlet in the unsupported area [1].

According to open data sources, before the early 1970s, there were no fully mechanized systems for top coal caving neither in front nor behind the powered roof support. The researches mostly aimed at improvement of the existing techniques via simplification of coal outflow processes using various outlet pans. By the early 1970s, French innovators succeeded in designing purpose-built fully mechanized systems for top coal caving with coal outlet in unsupported area in longwalls. The French know-how immediately came into notice of the Soviet engineers, and as early as the mid-1970, pilot fully mechanized longwall mining system KM-81V, with outlet of caved coal onto a conveyor placed in the rear of the roof support was developed and comprehensively tested [1]. Figure 1 shows a sketch of the powered roof support unit included in KM-81V.

At the same time, in Germany, a powered roof support system was designed for coal outlet onto a face conveyor arranged in front of the roof support. Figure 2 depicts an exemplary powered roof support with gravity flow of coal to a face conveyor.

\footnotetext{
*Corresponding author: nsm.nis@mail.ru
} 


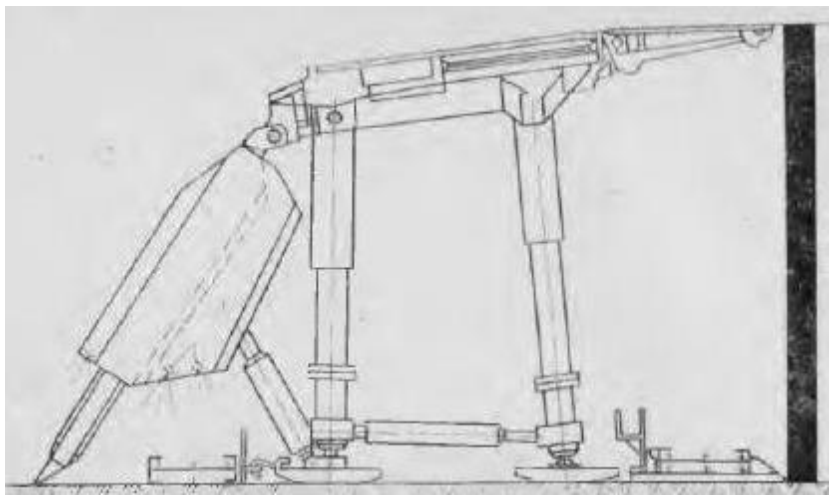

Fig. 1. Powered roof support unit within KM-81V system [2].

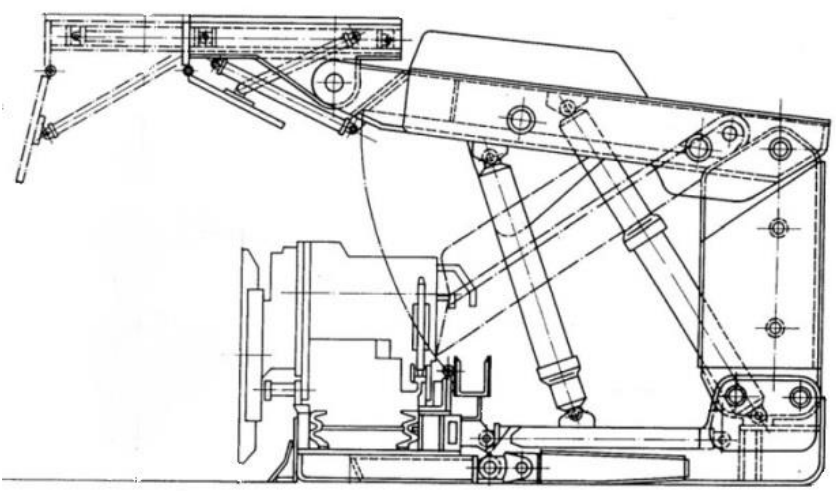

Fig. 2. Powered shield-type support VHP 730 with coal outlet to face conveyor, 1983 [3].

Technologically, the most interesting engineering solution was DT 4/400 LTCC roof support designed by Dowty in 1982 (Fig. 3). We know little about that prototype; however, this is a special class of powered roof supports with coal outlet to a rear conveyor [3].

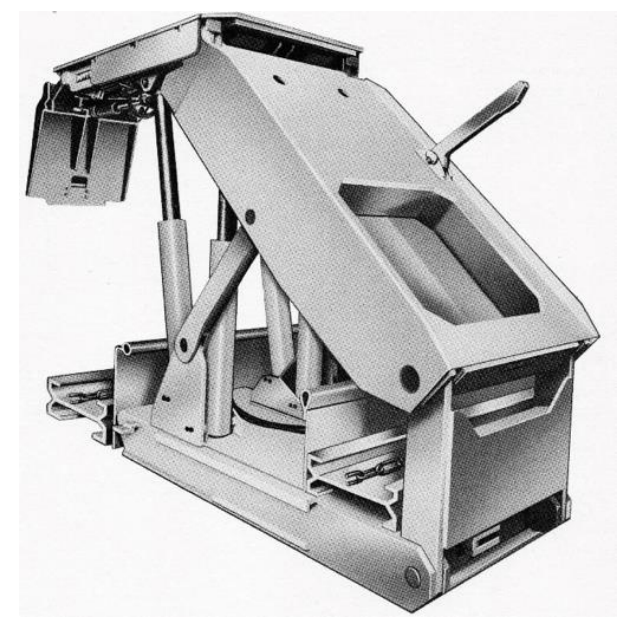

Fig. 3. DOWTY DT 4/400 LTCC roof support with rear conveyor [4]. 
Even though the USSR, France, Germany and Great Britain advanced so much in this engineering area, LTCC systems have found the widest application in China.

On the evidence of open data sources as of 2021, LTCC systems are mainly operated in China and Australia, and to some extent in Russia and in Turkey.

Historically, the USSR and, then, Russia went along the road of development and improvement of equipment for LTCC technology with coal outlet onto a conveyor arranged in supported area (hereinafter, the armored face conveyor AFC). The design efforts succeeded in overcoming of difficulties connected with the first-generation LTCC systems with gravity flow of coal to AFC, namely, dustiness, heavy losses of coal in the connection zones between roof support units, and low capacity of coal discharge. To that end, the coal outlet design was added with a feed apron, the size of the outlet was increased, and the gravity outflow was rejected. The powered feed apron and the steered gate valve included in the roof support design enabled adjustment of the outlet coal volume. Moreover, it became possible to implement simultaneous coal outlet in many support units (in groups up to a few tens of units) without the risk of AFC overload. The advances posed new challenges.

Mathematical modeling of coal outlet processes shows that efficient multi-point outlet needs that the outlet capacity of each roof support unit is maintained at the same preset level, without any overshoot $[5,6]$. In the former LTCC systems, not more than 10 support units were involved in simultaneous coal outlet without any control of the coal flow. The attending personnel observed when gangue started flowing from the outlet pan and shut off the outflow immediately. In the new-generation LTCC systems, it is physically impossible for a man to keep an eye on tens of support units in order to adjust coal outflow and to shut off the gate valves in due time. Thus, it is the long-felt need for the coal outlet process automation and sensor-based control capable to detect coal-gangue interface and to determine the outflow volume in real time. The simplest and natural approach to this issue is to employ these components from the advanced LTCC systems with AFC.

\section{Approaches to top coal caving automation}

The equipment and technology in LTCC with front-end conveyor and with rear-end conveyor are similar. For this reason, it can be expected that the automation problems are solved. However, the review of the open access information scantily describes automation of the coal-gangue interface detection. Coal flows out in automode. But how does it work? Syd S. Peng says in his book Longwall Mining that there is no coal-gangue interface detection procedure in Australian mines. Primarily, an operator determines the time period within which mostly coal flows from an open outlet. The LTCC automatics is set so that the flow gate above the conveyor is open for this time. In this fashion, we have that the LTCC equipment does not differentiate the flow composition. Moreover, the LTCC automatics is "unconscious" whether coal flows to the conveyor or not: the gate above the rear conveyor is opened at the preset place, the automatics keeps the preset time interval and, then, shuts off the gate. The outlet phase is terminated. Even less information is available on automated operation of Chinese LTCC systems. For example, Chinese CODCOZF 8000/22/35/ LTCC system employed in Olzheras-Novaya Mine has no equipment to control caved coal flow to the rear conveyor. This process is controlled manually. Availability of manual coal flow control on Chinese machines is also reported by the control system producers, for example, marco Systemanalyse und Entwicklung GmbH [7].

Using advanced IT applications in [8], marco Systemanalyse und Entwicklung GmbH described a coal-gangue interface detector based on seismic sensor Marco ps/ks $/ \mathrm{b}$ having a frequency range of $2.5-25000 \mathrm{~Hz}$. The sensor senses vibro-acoustic effects generated in rock mass when the powered roof support unit advances to the top coal caving zone. 
Computer processes the obtained signal and isolates a characteristic component of the vibro-acoustic effect generated in contact of rock and metal of the support unit structure. By measuring the level of the signal from rock-support interaction, it is possible to have an indirect judgment on the presence of gangue in the outlet flow. According to the open access data as of 2021, the system meant for the vibro-acoustic detection of coal-gangue interface for LTCC machinery with rear conveyor is at the prototype development stage and is not used in actual LTCC machines.

The LTCC technology makes no provision for the simultaneous outlet of caved coal flow from large groups of powered roof support units [9-11]. Outlet coal is loaded on the conveyor in the zone which is already passed by the main LTCC system, and cascading of coal from the conveyor on the longwall floor causes no troubles for the machinery operation. Accordingly, the outlet flow control in each support unit is not critical in this case. In case of the rear conveyor, the operating conditions at its worksite make the problem solution unreasonably expensive and technically difficult. Up to now the present paper authors have unsucceeded to find any description of an attempt to handling the problem connected with outlet flow volume determination per roof support unit for LTCC system with rear conveyor in open access sources.

\section{Feasibility of using advanced automation equipment in LTCC technology}

Thus, by now we have two key techniques for automated sensing of coal-gangue interface. These are the seismic analysis and setting the time frame. Let us discuss application feasibility of these techniques in LTCC systems with coal outlet to rear conveyor.

Seismic analysis. The authors believe this technique can become operable and efficient in LTCC systems with anticipated advance of the neural network analysis and with accumulation of sufficient learning sampling of signals. According to marco Systemanalyse und Entwicklung $\mathrm{GmbH}$ [7], the related research is in progress.

Considering the set objective, this technique is difficultly adaptable for: 1) the varied behavior of the outlet flow as against the LTCC systems currently in use, which requires a new learning sampling of signals for neural network, which is unavailable and unobtainable thus far; 2) the tight space interval within which rocks have contact with metal structures of roof support unit before entering the feeder, required to isolate the required signal; 3) the presence of the mobile apron feeder as gangue can enter the feeder together with coal and can generate signals comparable with the signals generated in rock-roof support metal contact; 4) the absence of the well-grounded theoretical or experimental data on coal and gangue distribution at the inlet of the outlet hole (in other words, it is unknown whether gangue 'drowns' in coal flow and touches the roof support unit, or, otherwise, coal acts as an envelope of the core gangue flow).

Time-frame setting. Being operated for a long time, this method provides a rough accuracy even in simple geological conditions in mines of Australia. In complex ground conditions in Russian coal fields, this technique will offer either unstable results per stages of outlet, or will results in large coal loss within a selected time horizon. For a LTCC system with outlet to rear conveyor, it is required to reduce the output for the selected time frame for some support units in order to adjust the load of the conveyor, which is not very critical when coal is outlet in the unsupported area. Generally speaking, the time-frame setting approach to the coal-gangue interface determination involves no expenses connected with new equipment engineering. On the other hand, in the conditions of coal outlet to a conveyor arranged in the supported longwall area, this technique reduces feasibility of the maximum coal outlet without the risk of large volume of gangue inrush to conveyor. 


\section{Conclusions}

The Longwall Top Coal Caving technology has been enjoying application for many decades. It has evolved from the hazardous manual procedure to the highly mechanized work. Despite all these achievements in mechanization, this paper authors failed to find out any open access data on fully automated LTCC systems. By 2021 the task of the automated coal-gangue interface detection at the acceptable accuracy such that the outlet window is closed when gangue approaches it, in LTCC systems with coal outflow on the conveyor arranged in the unsupported longwall area remains yet to be solved.

The problem connected with the coal-gangue interface determination is more essential for the LTCC with AFC. In this case, it is necessary to use a noncontact method of the rock flow composition analysis. The problem of outlet volume per roof support unit is also unsolved. The new-generation LTCC systems have the outlet zone in the supported area of longwall and the dust suppression facilities are available. Consequently, the promising way to meeting the challenges can be the computer vision technologies and the neural networks for image processing.

The reported study was funded by RFBR, project number 19-35-90075\19.

\section{References}

1. E.M. Dubrovsky (Ed.). Improvement of technologies and equipment for integrated automation of longwall top coal caving in flat seams (TSNIEIugol, Moscow, 1977)

2. Fully mechanized longwall mining systems and devices www.sv-barrisol.ru

3. Dung Le Tien, Longwall Top Coal Caving mechanism and cavability assessment: $\mathrm{PhD}$ thesis in Mining Engineering (Sydney, 2018)

4. 4/400 Tonnes Sub-Level Caving Shield Support www.dowtyheritage.org.uk

5. A.N. Starodubov, V.V. Zinoviev, et al., Simulation modeling in the analysis of longwall top coal caving regimes, in Proceedings of the $9^{\text {th }}$ Russian Conference on Simulation Modeling and Applications in Science and Industry (UGPU, Yekaterinburg, 2019)

6. A.N. Starodubov, V.V. Zinoviev, V.I. Klishin Analysis of LTCC regimes using simulation model, in Proceedings of the Conf. on Science-based Technologies of Mineral Mining and Use (SibSIU, Novokuznetsk, 2019)

7. Marco System Analysis and Development GmbH, www.marco.de

8. M. Reuter, M. Krach, U. Kiessling, Ju. Veksler, J. Fundament. Appl. Min. Sci., 4 (2), 263-269 (2017)

9. Efficient Mining of High Seams with Automated LTCC Operations: Mining Report, www.mining-report.de

10. S.A. Kizilov, et al. IOP Conf. Ser.: MSE, 865 (2020)

11. S.A. Kizilov, M.S. Nikitenko, E.A. Khudyntsev, Equipment control chart for adjustable coal outlet to AFC in LTCC technology, in Proceedings of the Conf. on Science-based Technologies of Mineral Mining and Use (SibSIU, Novokuznetsk, 2018) 